\title{
Development of Superconducting Focusing Quadrupoles for Heavy Ion Drivers
}

\author{
N. N. Martovetsky, R. Manahan, A. F. Lietzke
}

This article was submitted to

$17^{\text {th }}$ International Conference on Magnet Technology; Geneva, Switzerland; September 24-28, 2001

\section{September 10, 2001}

Lawrence

Livermore

National

Laboratory 


\section{DISCLAIMER}

This document was prepared as an account of work sponsored by an agency of the United States Government. Neither the United States Government nor the University of California nor any of their employees, makes any warranty, express or implied, or assumes any legal liability or responsibility for the accuracy, completeness, or usefulness of any information, apparatus, product, or process disclosed, or represents that its use would not infringe privately owned rights. Reference herein to any specific commercial product, process, or service by trade name, trademark, manufacturer, or otherwise, does not necessarily constitute or imply its endorsement, recommendation, or favoring by the United States Government or the University of California. The views and opinions of authors expressed herein do not necessarily state or reflect those of the United States Government or the University of California, and shall not be used for advertising or product endorsement purposes.

This is a preprint of a paper intended for publication in a journal or proceedings. Since changes may be made before publication, this preprint is made available with the understanding that it will not be cited or reproduced without the permission of the author.

This report has been reproduced directly from the best available copy.

Available to DOE and DOE contractors from the

Office of Scientific and Technical Information

P.O. Box 62, Oak Ridge, TN 37831

Prices available from (423) 576-8401

http:/ / apollo.osti.gov/bridge/

Available to the public from the National Technical Information Service

U.S. Department of Commerce 5285 Port Royal Rd., Springfield, VA 22161 http://www.ntis.gov/

OR

Lawrence Livermore National Laboratory Technical Information Department's Digital Library http://www.llnl.gov/tid/Library.html 


\title{
Development of Superconducting Focusing Quadrupoles for Heavy Ion Drivers
}

\author{
N. Martovetsky, R. Manahan, A.F. Lietzke
}

\begin{abstract}
Heavy Ion Fusion (HIF) is exploring a promising path to a practical inertial-confinement fusion reactor. The associated heavy ion driver will require a large number of focusing quadrupole magnets. A concept for a superconducting quadrupole array, using many simple racetrack coils, was developed at LLNL. Two, single-bore quadrupole prototypes of the same design, with distinctly different conductor, were designed, built, and tested. Both prototypes reached their short sample currents with little or no training. Magnet design, and test results, are presented and discussed.
\end{abstract}

Index Terms-Superconducting quadrupoles, focusing magnets, racetrack coils, APC conductor, Rutherford type conductor.

\section{INTRODUCTION}

$\mathrm{H}$ eavy ion fusion (HIF) drivers for an inertial confinement fusion reactor will require multi-aperture focusing quadrupole magnet arrays to guide the heavy ion beams to their target. A concept for a powerful, economical focusing magnet array for HIF, using simple racetrack coils, has been developed in collaboration between LLNL and LBNL [1]. The next major step in the development of the HIF driver, the High Current eXperiment (HCX), is currently under construction. It will use single-bore superconducting quadrupoles to focus one beam. To demonstrate the feasibility of the design principles for such magnet systems, we designed, built and tested two full-scale, single-bore prototypes under the following constraints: 1) meet the HCX requirements for a single beam experiment, 2) use design and fabrication technology that is relevant for a multi-beam HIF driver array.

\section{Design AND FAbrication of the HCX Prototypes}

\section{A. Design}

Figure 1 illustrates the relationship between the racetrack coils and the iron yoke for the two HCX quadrupole prototypes that were built and tested.

Manuscript received September 25, 2001.

This Work supported by the US Department of Energy under contract to the Lawrence Livermore National Laboratory (contract No. W-7405-Eng48.

N.M. and R.M. are with Lawrence Livermore National Laboratory, Livermore, CA 94550, USA (telephone (925) 422 4269, e-mail: martovetsky1@1lnl.gov)

A.F.L. is with Lawrence Berkeley National Laboratory, Berkeley, CA, 94720, USA, (telephone (510) 486 4572, e-mail: aflietzke@lbl.gov)

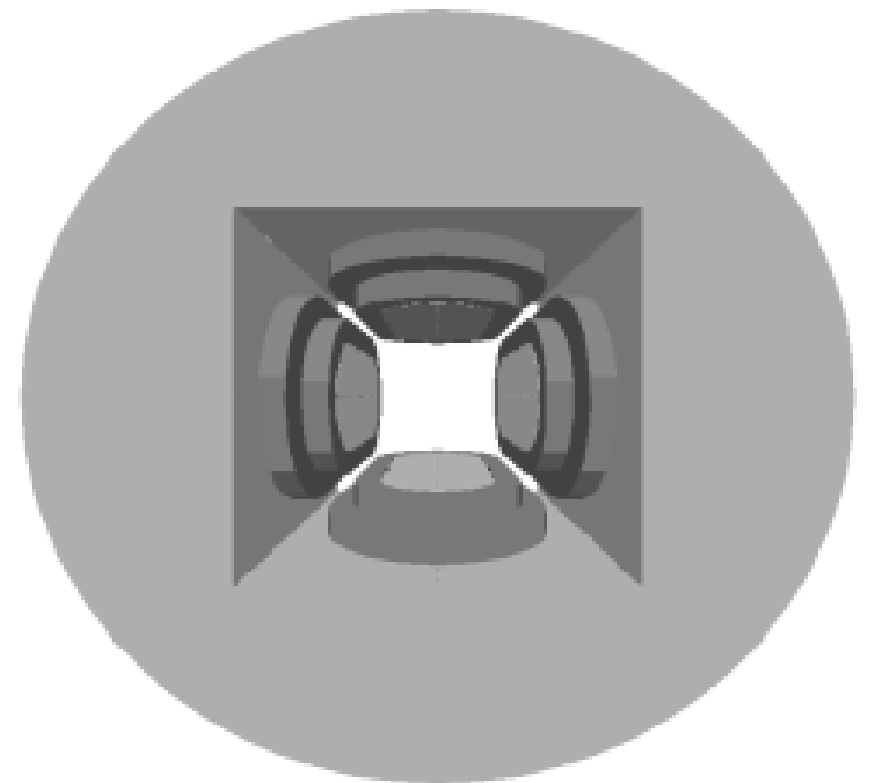

Fig. 1. HCX quadrupole prototype windings and iron yoke (without supporting structure for clarity).

The magnetic yoke and the ferromagnetic cores inside the racetrack windings increased the maximum field gradient by about $25 \%$. The OD of the yoke was $260 \mathrm{~mm}$, and was chosen to minimize the stray field outside the magnet. The length of the coils was $122 \mathrm{~mm}$, with an iron yoke that was $136 \mathrm{~mm}$ long. To simplify the design, round racetrack ends, with no spacers, were used in the winding pack. This simplified fabrication and minimized coil costs, but did not minimize either the error fields, or the peak field in the winding. Since, for this application, the integral field quality is more important than the local details, the quadrupole was designed so that the field errors from straight runs opposed the field errors from the round ends, in a manner to achieve good integral field quality.

The parameters of the quadrupole, its gradient and error fields are listed in Table 1, wherein b2c is the central quadrupole harmonic, and b6, b10 and b14 are error field harmonics normalized to b2c, and integrated over a length comfortably longer than the quadrupole length. The error harmonics were calculated at a $20 \mathrm{~mm}$ radius, while the distance between the beam axis and the closest winding plane was $36 \mathrm{~mm}$. Extensive simulations of particle trajectories showed that the listed field quality was quite acceptable, with a comfortable margin.

TABLE 1 ChaRACteristics OF APC HCX PROTOTYPE 


\begin{tabular}{|l|c|}
\hline Nominal current: & $2760 \mathrm{~A}$ \\
\hline Winding pack current density: & $500 \mathrm{~A} / \mathrm{mm} 2$ \\
\hline Field gradient: & $106 \mathrm{~T} / \mathrm{m}$ \\
\hline Nominal peak field in the winding: & $6.18 \mathrm{~T}$ \\
\hline Winding length: & $122 \mathrm{~mm}$ \\
\hline Effective focusing length: & $101 \mathrm{~mm}$ \\
\hline b6/b2c error: & $5 \mathrm{E}-4$ \\
\hline b10/b2c error: & $-1.6 \mathrm{E}-4$ \\
\hline b14/b2c error: & $0.6 \mathrm{E}-4$ \\
\hline
\end{tabular}

\section{B. Fabrication}

The racetracks were assembled in quadrants. Each quadrant consisted of two racetrack coils, "inner" and "outer", that were inserted into the coil holders after winding (Fig. 2). Each racetrack coil is a double-layer pancake, which avoided internal joints within the winding pack. After the coil was inserted in the coil holder, the ferromagnetic pole-inserts were installed. These inserts had several functions: 1) they prestressed the winding pack against the coil holder, 2) they increased the field gradient, and 3) they decreased the peak field on the coil's pole-turn. The inserts had gaps and wedges to pre-stress the winding pack outward against the wall of the coil-holder. The pre-stress for the straight runs of the racetrack was applied to match the Lorentz stress expected at the nominal current. Each quadrant was then vacuum impregnated with epoxy resin to form a solid block with protruding leads (Fig. 3). Four blocks were assembled, and the joints were solder-spliced, to form the quadrupole coil assembly. This assembly was surrounded with iron yoke blocks, which were captured and tightly compressed by a welded outer shell.

\section{Conductor}

Two types of conductor were tested. Both conductors had rectangular cross section, with a height of $4.05 \mathrm{~mm}$, and both fit the same coil holder. The rectangular form facilitated a high packing factor, and a stiff winding pack, with good structural properties. The first prototype used Artificial Pinning Centers (APC) monolithic conductor from Supercon, Inc. The second prototype used Rutherford cable, with 13 SSC-outer-layer strands. The conductor parameters are summarized in Table 2.

Although not an "off-the-shelf" product, the monolithic APC conductor had several attractive features compared to the more conventional 13-strand Rutherford cable option or a monolithic conductor made of conventional multifilamentary wire:

1) The APC is not that sensitive to the amount of cold work as a standard monofilament product, therefore it is easier to obtain a small filament size and high jc on such a large cross section as $4 \mathrm{~mm}^{2}$ conductor than for the standard strand made out of a small billet and low cold work.

2) The APC has a potential to be less expensive in mass production [2], than the standard strand.

3) The monolith conductor saves significant cost expense associated with cabling.

We also tried to increase the winding pack current density by raising $\mathrm{NbTi}$ to $50 \%$ of the conductor cross section to obtain higher gradient. Of course, a standard multifilamentary conductor or HTC conductor could replace the APC monolithic conductor if desired.

TABLE 2. PARAMETERS OF THE CONDUCTORS USED FOR HCX PROTOTYPES

\begin{tabular}{|l|c|c|}
\hline & APC & Rutherford \\
\hline Construction: & $\begin{array}{c}\text { monolit } \\
\text { h }\end{array}$ & 13 strand \\
\hline Twist pitch of the conductor: & $37 \mathrm{~mm}$ & $32 \mathrm{~mm}^{*}$ \\
\hline Width: & 1.00 & $1.17 \mathrm{~mm}$ \\
& $\mathrm{~mm}$ & \\
\hline Height: & 4.05 & $4.05 \mathrm{~mm}$ \\
& $\mathrm{~mm}$ & \\
\hline NbTi:Cu cross-section ratio: & $1: 1$ & $1: 1.8$ \\
\hline
\end{tabular}

*strand twist-pitch is $13 \mathrm{~mm}$

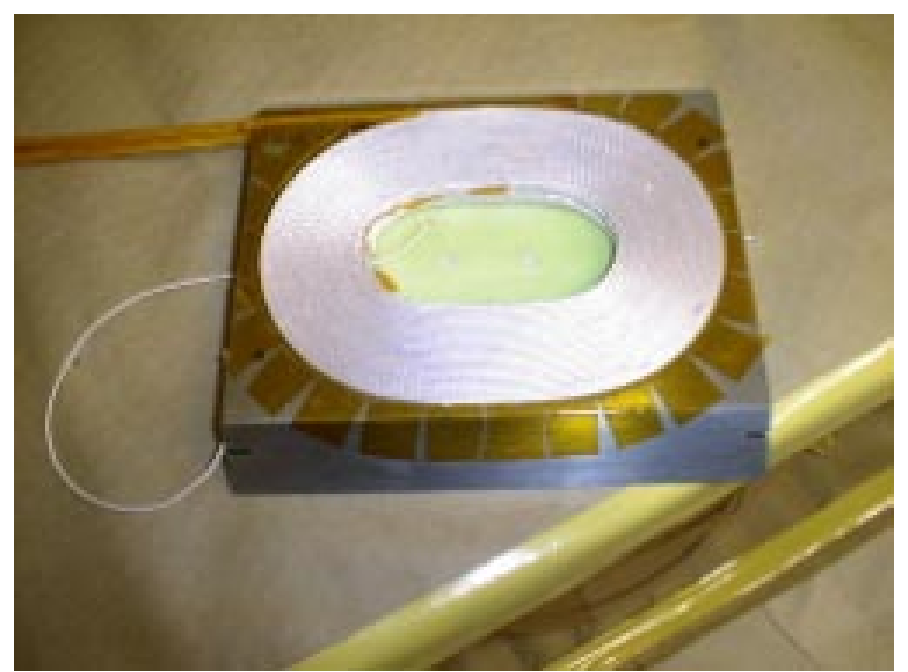

Fig. 2. Outer coil in its coil holder. Its internal voltage tap, eventually attached to the central point of the double boil, is seen on the left.

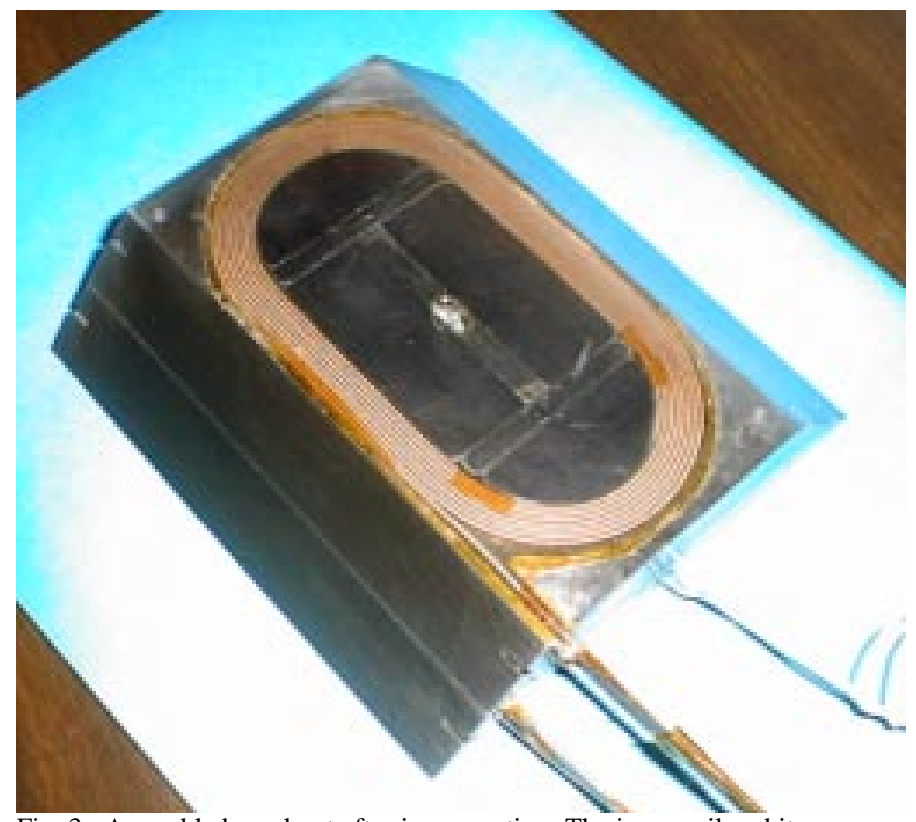

Fig. 3. Assembled quadrant after impregnation: The inner coil and its central voltage tap are visible. The outer coil is underneath.

The final rectangular cross-section of the APC conductor was obtained by rolling a twisted round wire. As this deformed and moved the superconducting filaments within the wire, we were concerned about anisotropic reduction of the critical 
current density [3]. With less copper in the cross section to absorb the displacement and deformation of the filaments during rolling, the previously observed degradation might be worse. To investigate the degradation in our case, a round multi-filamentary wire, with $50 \% \mathrm{NbTi}$, was rolled to aspect ratios of $1: 3$ and 1:4. The critical currents were measured at BNL with the magnetic field parallel and perpendicular to the flat side of the conductor.

Measurements for the 1:4 aspect ribbon revealed that the $I_{c}$ at $5 \mathrm{~T}$ increased by $5 \%$ when the magnetic field was parallel to wide side, and decreased by $7 \%$ when the magnetic field was perpendicular. As this was similar to the previously reported measurements [3], with lower $\mathrm{NbTi}$ content, we felt encouraged, especially since there is only a small perpendicular component of field in the peak field area for our application. We believe that the aspect ratio of the conductor could be made significantly higher, should that be advantageous, judging by similarity of results from [3].

\section{TESTING}

Both prototypes were tested at LBNL in a cryostat filled with liquid helium. The three voltage taps that were attached to each coil (inlet, outlet and center-tap) allowed us to monitor the voltages from all half-coils and all inter-coil joints. The center-tap also allowed an unambiguous determination of which half-coil started quenching first.

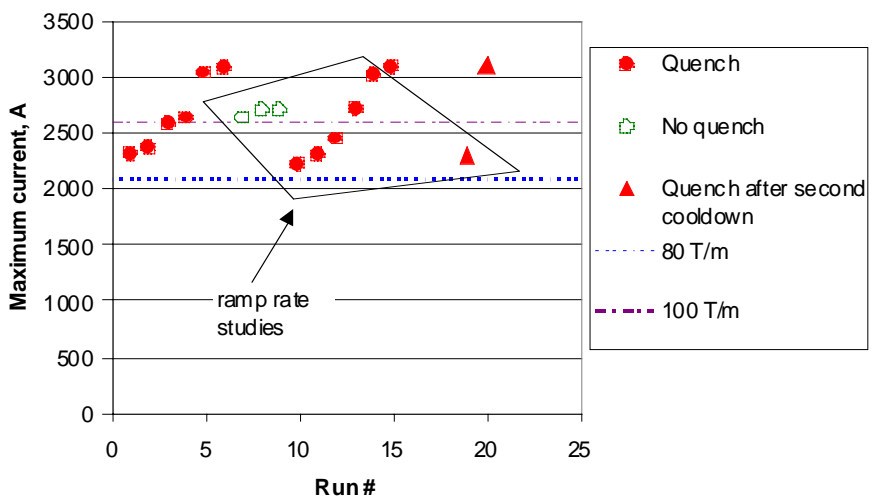

Fig. 4. Training history of the APC quadrupole prototype.

\section{A. APC quadrupole performance}

\section{1) Training}

The APC quadruple training history is shown in Fig. 4. The HCX operating gradient $(80 \mathrm{~T} / \mathrm{m})$ was exceeded on the first attempt, with the magnet ramped at a steady $5 \mathrm{~A} / \mathrm{s}$. The ramprate was decreased sequentially to $1.25 \mathrm{~A} / \mathrm{s}$ as the magnet trained toward the predicted short-sample current. Four quenches were required before achieving this goal. All training quenches originated within $\sim 3 \mathrm{~mm}$ of the central voltage tap, where 1) the field was highest, and 2) the resinrich voltage-tap access region may have cracked, and initiated quenching. Eliminating of the central voltage-taps might have improved the training performance.

At the maximum current, the peak field in the conductor was calculated to be 6.9T. The current densities exceeded $765 \mathrm{~A} / \mathrm{mm}^{2}$ (conductor), 562A $/ \mathrm{mm}^{2}$ (winding-pack), and $1530 \mathrm{~A} / \mathrm{mm}^{2}$ (copper), all remarkably high for $\mathrm{NbTi}$ conductor.

\section{2) Ramp rate sensitivity}

After the ultimate current was achieved, we studied the ramprate sensitivity, even though no firm ramp-rate requirement existed for the HCX quads, and the monolith APC conductor was not expected to tolerate rapidly changing fields very well. The results (Fig.5) revealed that the magnet could be successfully charged to the ultimate current at $10 \mathrm{~A} / \mathrm{s}$, and to the HCX operating point $(80 \mathrm{~T} / \mathrm{m})$ at $50 \mathrm{~A} / \mathrm{s}$. However, above

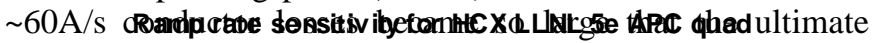
current decreased precipitously. This performance is expected to greatly exceed the ultimate HCX requirements.

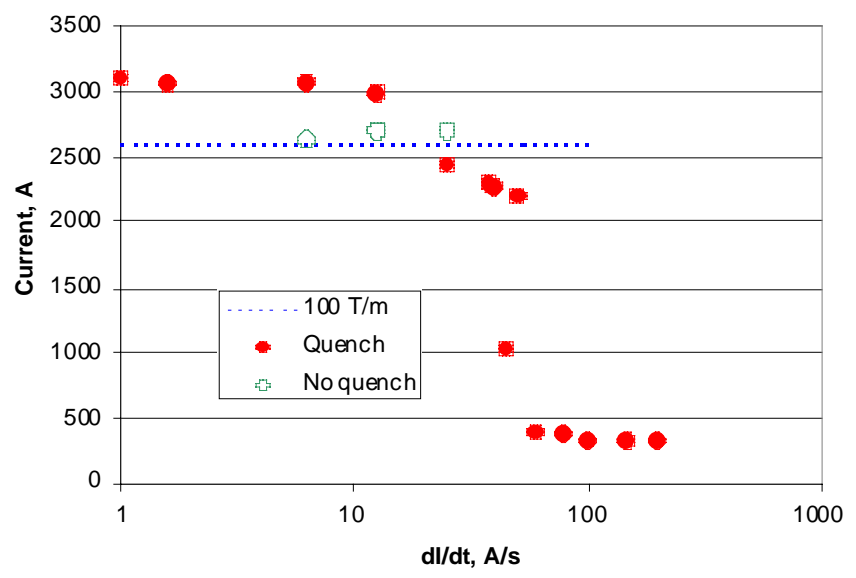

Fig. 5. Ramp rate sensitivity study for the APC quadrupole prototype

\section{3) Joint performance}

Joint resistance measurements showed that all joints were acceptable for HCX operation. The worst joint had a resistance of $2.5 \mathrm{nOhm}$ at $2700 \mathrm{~A}$, with most of the joints showing about $1 \mathrm{nOhm}$ or less.

4) Protection

Magnet protection with such a high $\left(1530 \mathrm{~A} / \mathrm{mm}^{2}\right)$ copper current density was of considerable concern. We used a $50 \mathrm{mOhm}(\mathrm{V}<150 \mathrm{~V})$ dump-resistor to reduce magnet heating. We discovered that the magnet resistance exceeded the dump resistance extremely quickly after quench origination. This resulted from rapid spreading of the normal zone, facilitated by the high copper current density, and especially rapid propagation to other layers and coils. As a result, the magnet absorbed most of its stored energy. Furthermore, the energy was distributed very uniformly, minimizing stresses from thermal inhomogeneities. We classified the magnet as "self-protective", at least in this rendition. This was inadvertently tested on the last quench of the first thermal cycle, when a fault-detector failure caused a complete dump system failure, as well as a slow ( $600 \mathrm{~ms})$ power supply turn-off (triggered by magnet over-voltage). Despite such a catastrophic protection failure, the magnet suffered no measurable damage, and required no training during the second cool-down (Fig. 4).

\section{B. Rutherford cable quadrupole performance}

The second quadrupole prototype, with Rutherford cable, also exceeded its intended operational level (2800A) when it achieved 2952A on its first ramp to quench. Including subsequent ramp-rate quenches, a total of 17 quenches were experienced during the test campaign (Fig. 6). The maximum current (3009A) was observed with a 20A/s ramp rate, while 
the minimum current at slower ramp rates was 2950A, indicating that the training was essentially nonexistent.

The ramp rate dependence was substantially better than that observed for the APC prototype. The maximum achievable current remained basically constant up to $200 \mathrm{~A} / \mathrm{s}$. This is believed to be due so tow sivity for HCX

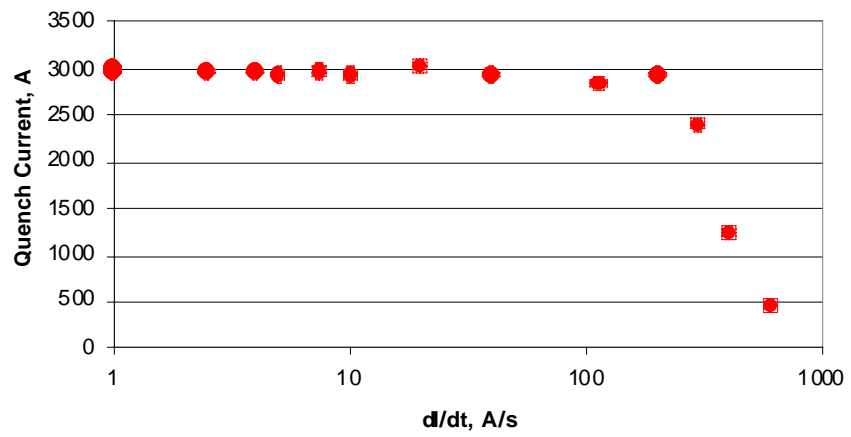

Fig. 6. Ramp-rate dependence (all quenches) for Rutherford cable protoquadrupole.

The joint resistances were all acceptable, but showed a larger variation than the APC prototype. The worst joint had a resistance of $6 \mathrm{nOhm}$ at $3000 \mathrm{~A}$, while most of the joints exhibited around $1 \mathrm{nOhm}$.

The performance of both prototypes relative to each other, their design goals, and their short sample dependencies is shown in Fig. 7. The APC conductor's critical current measurements were performed by Arup Ghosh (BNL). The Rutherford cable data was calculated from strand measurements, and downward-adjusted for an $8 \%$ cabling degradation (expected from strand deformation with a $92 \%$ cable compaction). The superior performance of the monolithic, low-copper APC quadrupole prototype is clearly visible in its $15 \%$ higher maximum focusing power.

\section{CONCLUSION}

Two HCX quadrupole prototypes, with distinctly different NbTi conductor, were designed, built, and tested. Both prototypes exceeded their proposed operating currents on the first attempt, and achieved their ultimate short-sample predictions, with little or no training, and no unexpected degradation. The maximum achieved average current densities exceeded $765 \mathrm{~A} / \mathrm{mm}^{2}$ (conductor), $562 \mathrm{~A} / \mathrm{mm}^{2}$ (winding-pack), and $1530 \mathrm{~A} / \mathrm{mm}^{2}$ (copper). The maximum achieved gradient was calculated to be $118 \mathrm{~T} / \mathrm{m}$.. The joint resistances and ramp-rate sensitivities were also acceptable for HIF driver focusing magnets.

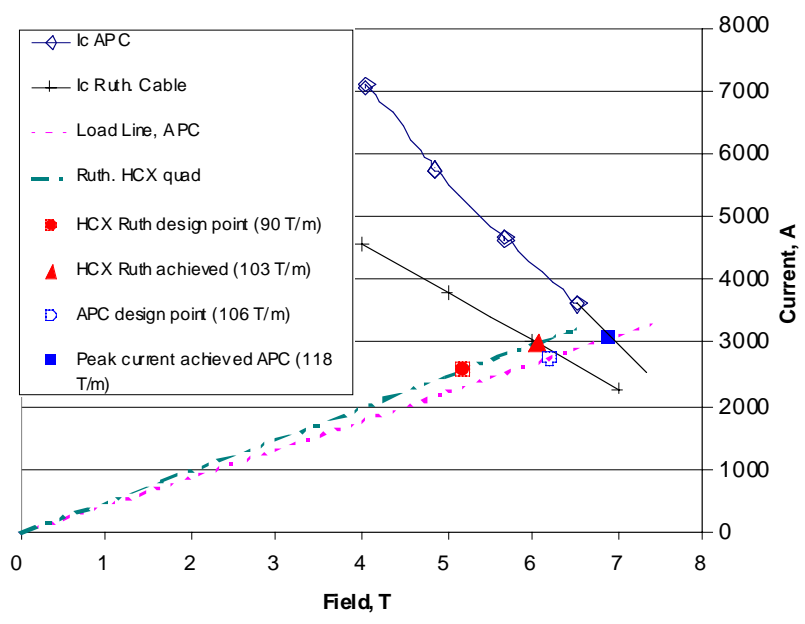

Fig. 7. Comparison between the two prototype performances and their short sample predictions.

These successes demonstrated:

1) The basic magnet design concept, fabrication approach, and associated racetrack technology collectively represent a reliable candidate for future $\mathrm{HCX}$ focusing magnets.

2) Since many elements from this prototype work can be directly applied to multi-beam magnet arrays, a viable technology also exists for future HIF driver focusing arrays.

3) The present APC conductor technology can successfully provide a high average current density in a large cross-section from a small billet, making it a more attractive option for small, highly optimized magnet coils than conventional Rutherford cable (especially for low field applications).

\section{ACKNOWLEDGMENT}

The authors are very grateful to Steve Lund, Peter Seidl, Roger Bangerter, Ron Scanlan, Steve Gourley and GianLuca Sabbi (all LBNL), Bick Hooper, Grant Logan (LLNL), for support and useful discussions, Don Podesta (LLNL), for help in fabrication, Terry Wong (Supercon Inc), for fabrication of the APC conductor with high $\mathbf{J}_{c}$, Arup Ghosh (BNL), for the $I_{c}$ measurements, Hem Kanithi, IGC, for sample preparation for the anisotropy studies, and Paul Bish and Doyle Byford for magnet test preparations and test facility operation.

\section{REFERENCES}

[1] N. Martovetsky, R. Manahan, "Focusing Magnets for HIF based on Racetracks", IEEE Transactions on Applied Superconductivity v.11, N1, March 2001, p.1506-1509

[2] Ron Scanlan, Terry Wong, private communications.

[3] M. Garber, T.Luhman, W. Sampson and M. Suenaga, Critical current optimization of Isabelle braid, Isabelle Project Technical note No 315, BNL, September 1, 1981 


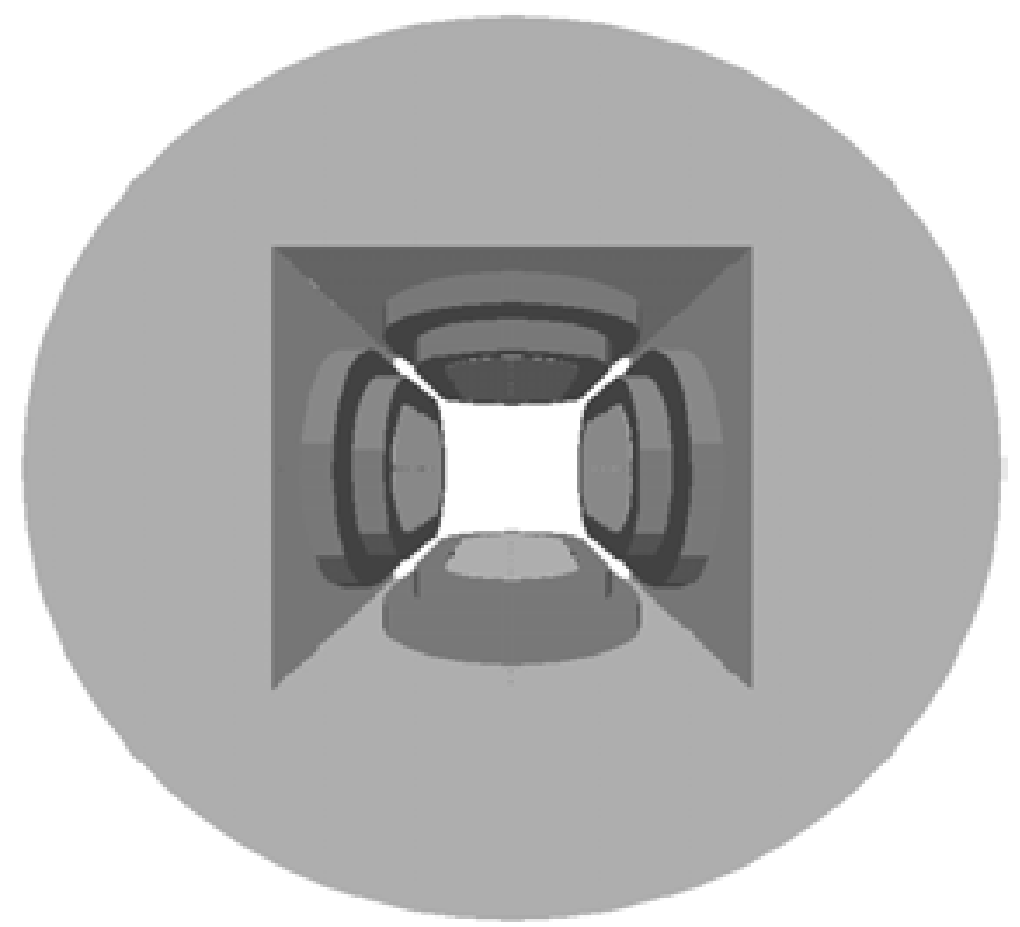

Fig. 1. HCX quadrupole prototype windings and magnetic yoke (without supporting structure for clarity).

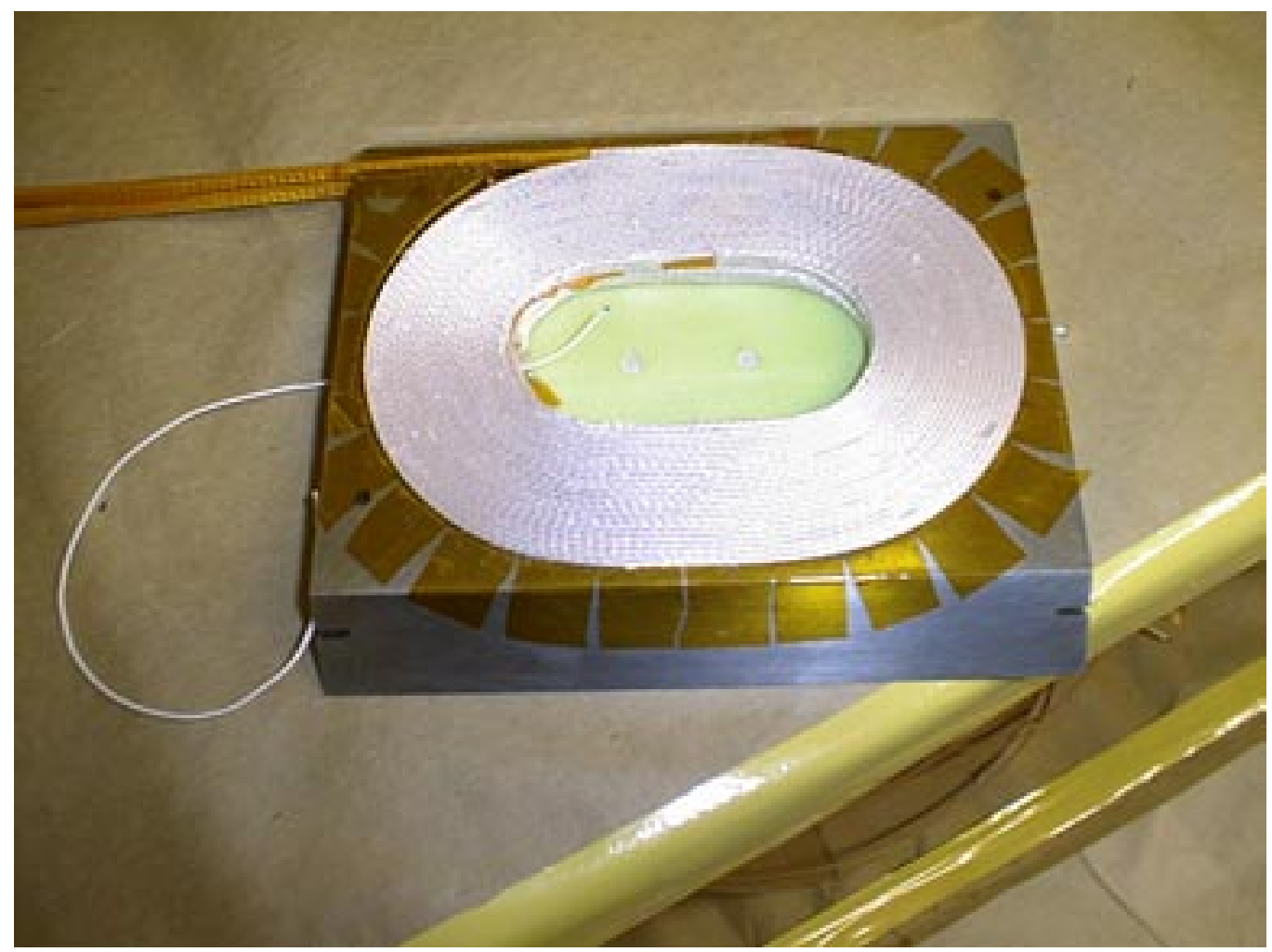

Fig. 2. Outer coil in its coil form. Its internal voltage tap, eventually attached to the central point of the double boil, is seen on the left. 


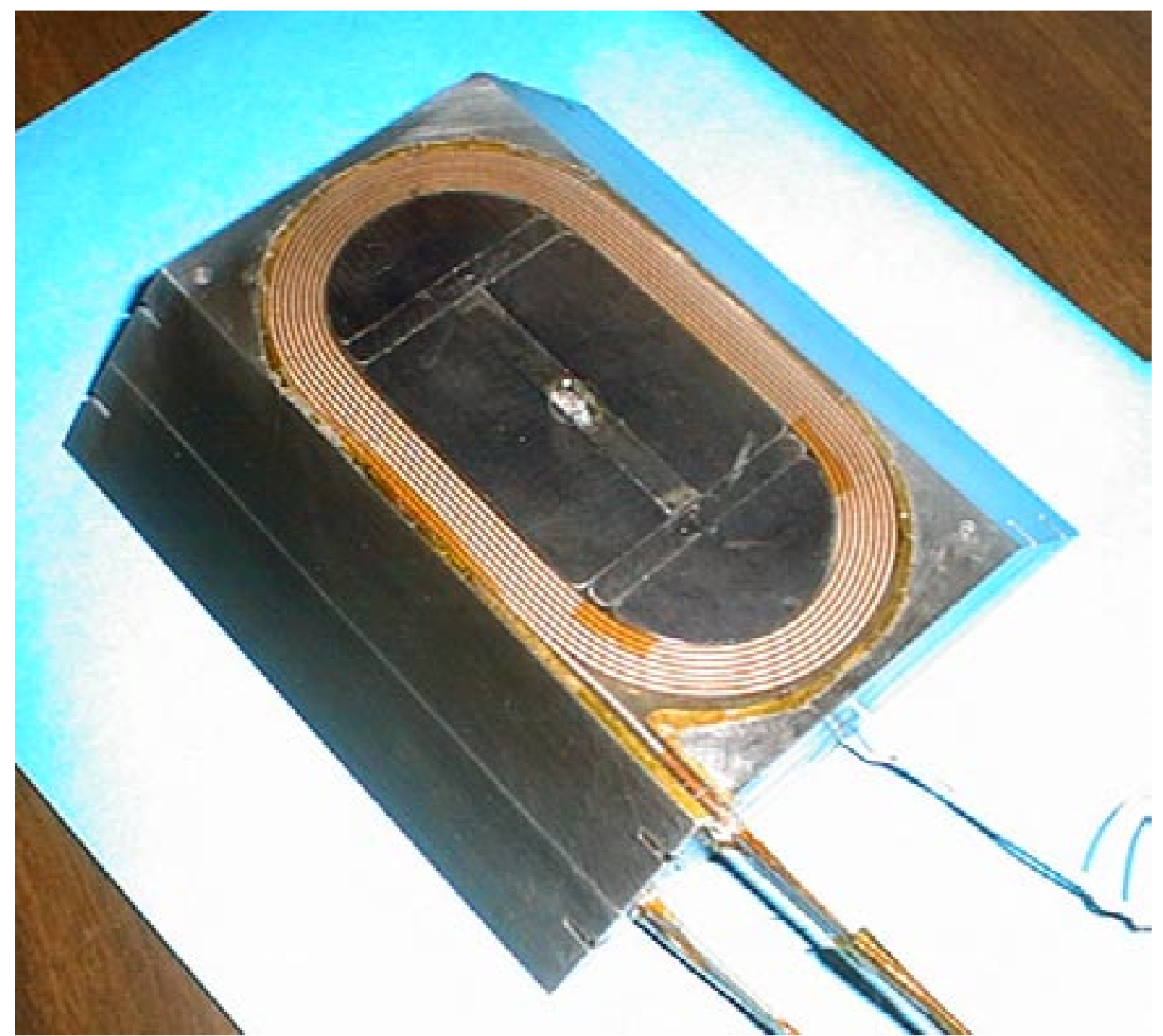

Fig. 3. Assembled quadrant after impregnation. The inferest phistory voltage tap are visible. The outer coil is underneath.

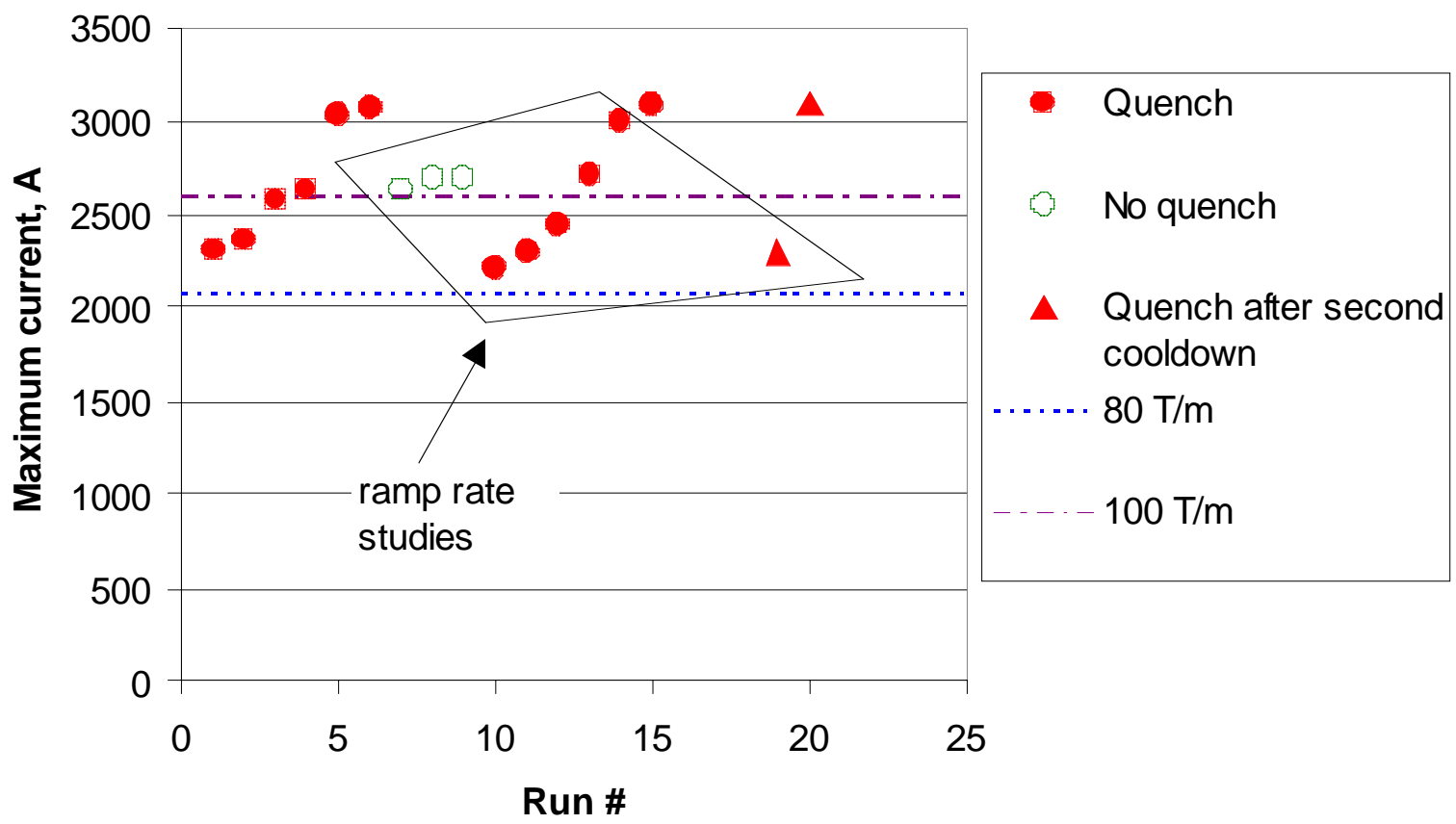

Fig. 4. Training history of the APC quadrupole prototype. 


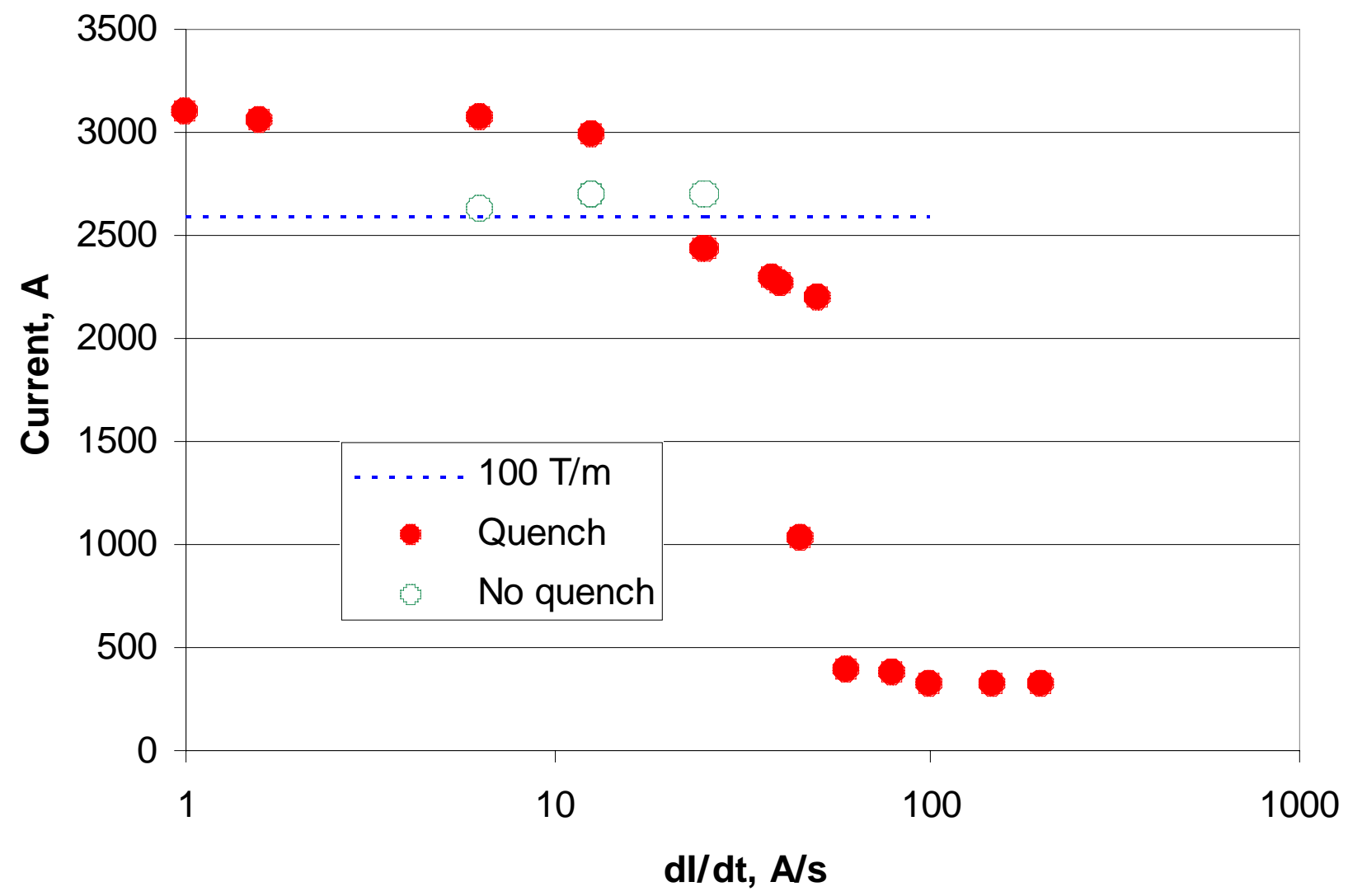

Fig. 5. Ramp rate senRamp, ratesensitivity,yfor HCX LLNL 5e Ruth quad

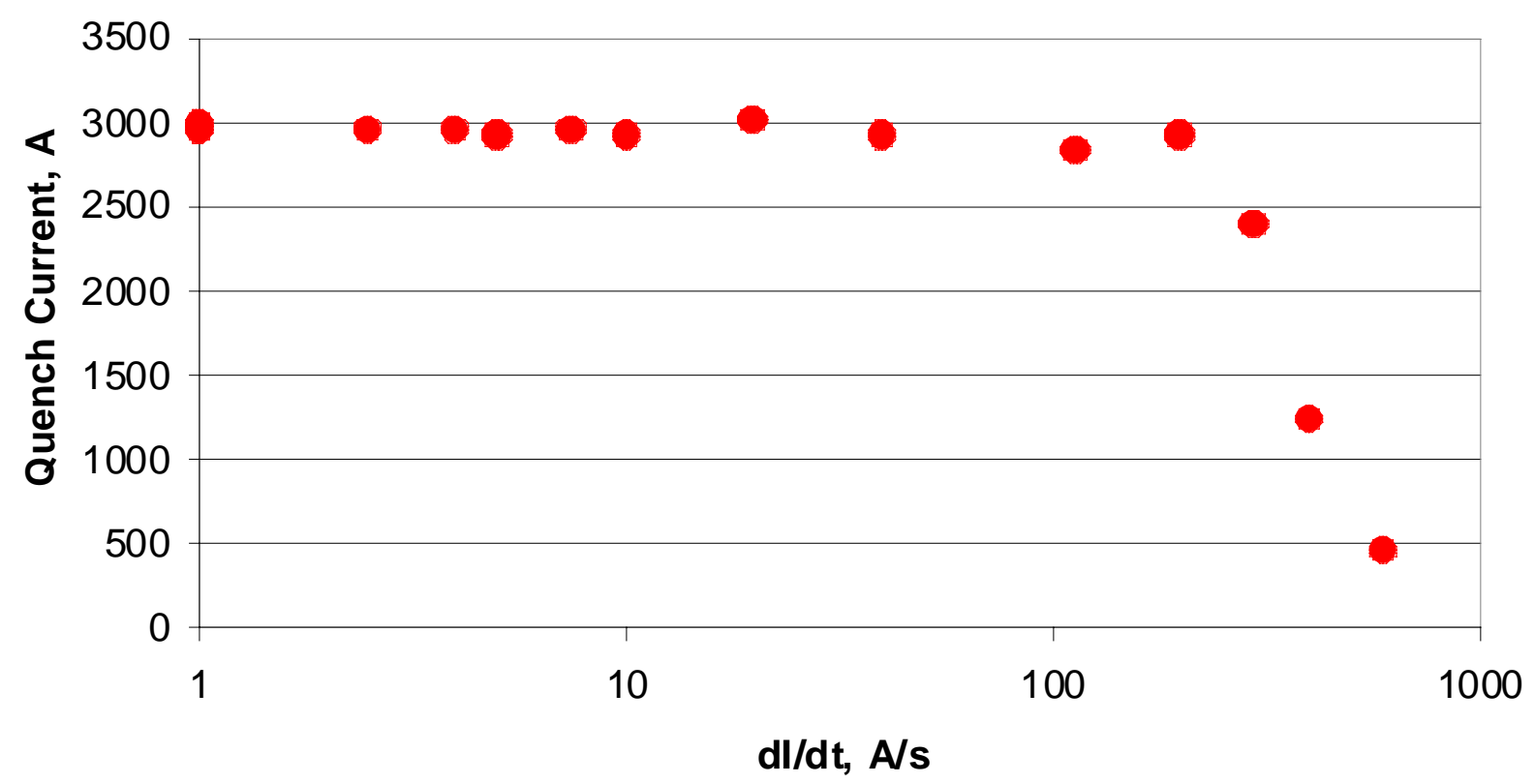

Fig. 6. Ramp-rate dependence (all quenches) for Rutherford cable proto-quadrupole. 


\section{LLNL HCX rrototypes: ANL vS hutnerrora}

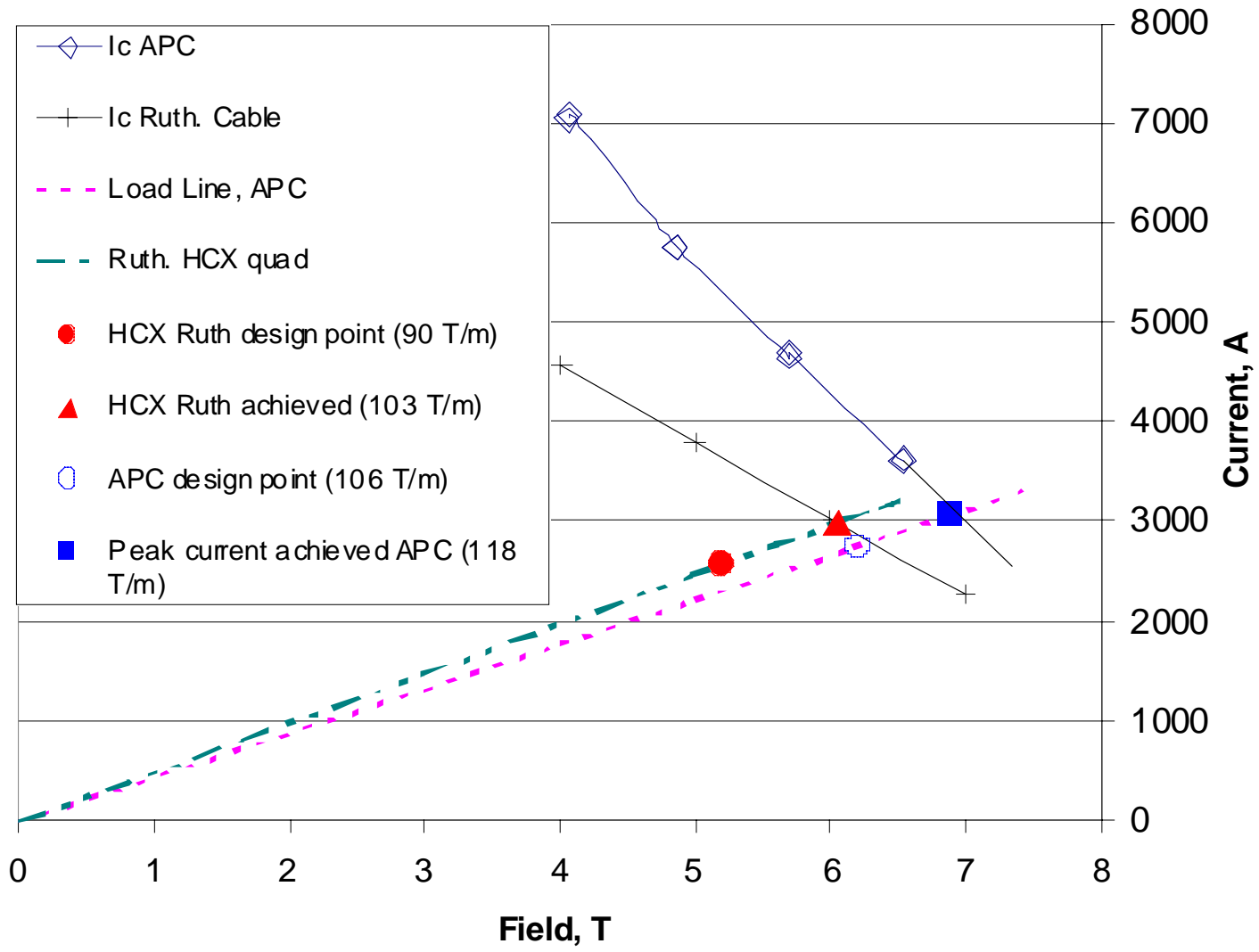

Fig. 7. Comparison between the two prototype performances and their short sample predictions.

TABLE 1 CHARACTERISTICS OF APC HCX PROTOTYPE

\begin{tabular}{|l|c|}
\hline Nominal current: & $2760 \mathrm{~A}$ \\
\hline Average current density: & $500 \mathrm{~A} / \mathrm{mm} 2$ \\
\hline Field gradient: & $106 \mathrm{~T} / \mathrm{m}$ \\
\hline Peak field in the winding: & $6.18 \mathrm{~T}$ \\
\hline Winding length: & $122 \mathrm{~mm}$ \\
\hline Effective focusing length: & $101 \mathrm{~mm}$ \\
\hline b6/b2c error: & $5.0 \mathrm{E}-4$ \\
\hline b10/b2c error: & $-1.6 \mathrm{E}-4$ \\
\hline b14/b2c error: & $0.6 \mathrm{E}-4$ \\
\hline
\end{tabular}


TABLE 2. PARAMETERS OF THE CONDUCTORS USED FOR HCX PROTOTYPES

\begin{tabular}{|l|l|l|}
\hline & APC & $\begin{array}{l}\text { Rutherfor } \\
\mathrm{d}\end{array}$ \\
\hline Construction: & monolith & 13 strand \\
\hline Twist pitch of conductor: & $37 \mathrm{~mm}$ & $32 \mathrm{~mm} *$ \\
\hline Width: & $1.00 \mathrm{~mm}$ & $1.17 \mathrm{~mm}$ \\
\hline Height: & $4.05 \mathrm{~mm}$ & $4.05 \mathrm{~mm}$ \\
\hline NbTi:Cu ratio: & $1: 1$ & $1: 1.8$ \\
\hline
\end{tabular}

*strand twist pitch is $13 \mathrm{~mm}$ 
University of California

Lawrence Livermore National Laboratory

Technical Information Department

Livermore, CA 94551

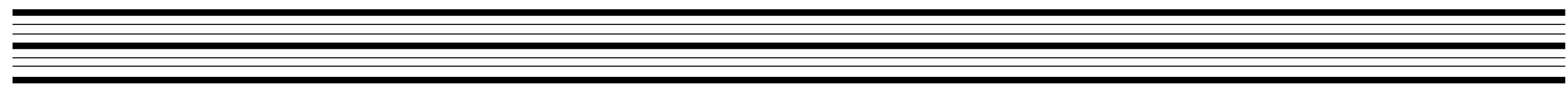

